\title{
A VUELTAS CON 1892. VIOLENCIA Y MILENARISMO EN LA FRONTERA NORTE DE MÉXICO*
}

POR

\author{
SALVADOR BERNABÉU ALBERT \\ Escuela de Estudios Hispanoamericanos, CSIC
}

«Somos hombres al igual que los mexicanos: podemos hacerles lo que nos han hecho» (Gerónimo, Memorias)

Mientras España y otros países europeos y americanos celebraban el IV Centenario del Descubrimiento de América, en 1892, los habitantes del norte de México conocieron las noticias de la última incursión apache en territorio mexicano y la sublevación de los vecinos del pequeño poblado de Temochic. Ambos sucesos nos sirven para estudiar la situación de la violencia generalizada en el Norte y el nacimiento de un sentimiento de libertad, independencia y malestar entre las autoridades gubernativas que desembocaría en la revolución de 1910.

\section{NUEVAS VISIONES DE UN AÑO PASADO.}

Hay personajes históricos que han seducido más que otros a los escritores. También hay años que gozan de mayor popularidad; cantos de sirenas que seducen a los historiadores y convocan a los impacientes de fama, oro y trabajos. Este es el poder del lenguaje, que inventa memorias a golpe de semblantes y fechas del calendario. Años que, con sólo pronunciarlos, provocan en un país, un colectivo o en los individuos un cúmulo de sensaciones especiales que lo distinguen de los que lo precedieron o lo siguieron. Años instalados en la memoria individual o colectiva dotados de cierta aureola mágica, como ha ocurrido con el que acabamos de dejar: 1998, primer centenario de aquél 98 del siglo XIX, al parecer, menos desastroso para sus contemporáneos que para los historiadores que lo crea-

\footnotetext{
* Trabajo realizado dentro del Proyecto de Investigación PB96-0868 (DGES).
} 
ron. Otro año significativo, un poco más lejano, fue 1992. En ese año, los americanistas fuimos convocados a re-leer y re-escribir el pasado de un continente y los contenidos de una especialidad histórica. En mi actividad investigadora, no es ese año, sino 1892 el que ocupó buena parte de mis preocupaciones históricas de los primeros años, fruto de los cuales aparecieron una monografía y varios artículos sobre el IV Centenario del Descubrimiento de América ${ }^{1}$. Así es recordado 1892 para muchos historiadores: el año en que varios países europeos y americanos fueron invitados para ensalzar el primer viaje colombino. Sin embargo, los nuevos derroteros de mi investigación me han llevado a dotar a ese año de nuevas significaciones que han re-inventado mi particular memoria de ese año ${ }^{2}$. Nuevas lecturas de esa mágica fecha que lo enriquecen y lo redefinen en un nuevo ejercicio de invención histórica, compartido, sin saberlo hasta ahora, con un lejano grupo de historiadores.

En 1892 se produjo la última incursión de un grupo apache en territorio mexicano. Procedían de una reserva norteamericana, donde habían sido recluidos desde finales de los años ochenta tras una prolongada guerra de exterminio con los ejércitos norteamericanos y las compañías guerreras de Chihuahua, Sonora y otros Estados fronterizos. El cónsul mexicano en Deming, Nuevo México, escribió un escueto oficio el 15 de agosto de 1892 a sus superiores, en el que comunicaba que unas cuantas familias perseguidas por el ejército de los Estados Unidos cruzaban la frontera. Postrero documento de una cruenta y desigual batalla que había polarizado la historia del Norte de México desde el siglo XVI. A la vez, 1892 fue el año de irrupción de un nuevo conflicto social incubado en numerosos territorios norteños cuando el repliegue del peligro indio se hizo manifiesto. Un conflicto entre los rancheros, abandonados a su suerte por años, y los beneficiados del régien porfirista. En 1892, el pueblo de Tomóchic (Chihuahua) fue arrasado por las fuerzas gubernamentales, convirtiéndose en un símbolo de la resistencia a Porfirio Díaz y un antecedente privilegiado de la Revolución Mexicana ${ }^{3}$.

1 1892. El IV Centenario del Descubrimiento de América en España, Madrid, CSIC, 1987; «El IV Centenario del Descubrimiento de América en la coyuntura finisecular (1880-1893)», $R e$ vista de Indias, vol.XLIV, 1984 pp. 345-366; «La Armada Española en el IV Centenario del Descubrimiento de América», Revista de Historia Naval, vol.XII, 1986 pp. 67-82; «Los justos títulos. Un acercamiento crítico a cien años de ideas sobre 1492», Históricas, México, núm.35 (mayoagosto 1992) pp. 27-41; y «El Centenario interminable. Contenidos ideológicos y culturales del IV y V Centenario de 1492», Lateinamerika-Studien, núm.37, 1995, pp. 9-27.

2 Sobre el tema, véase Pierre NoRA y otros, Les Lieux de mémoire, 3 vols., París, 1984-1986.

3 Antonio SABORIT, Los doblados de Tomóchic. Un episodio de historia y literatura, México, Cal y arena, 1994, p. 14.

R.I., $1999, \mathrm{n}^{\circ} 216$ 


\section{LA FRONTERA: LINEA Y ESPACIO DE CONTIENDA.}

La línea fronteriza establecida por el tratado Adams-Onís (1819) entre España y los Estados Unidos de América otorgaba a la nueva nación mexicana, tras la independencia en 1821, una inmensa porción de terrenos poco explorados. La frontera se iniciaba en el golfo de México a la altura del río Sabinas y se dibujaba en línea recta remedando el grado 32 de latitud Norte, siguiendo por el pueblo de Taos en Nuevo México, Arizona y California -incluyendo importantes porciones de Colorado, Nevada y Utah- hasta finalizar en el famoso puerto de San Francisco. La frontera era una invención literaria, cartográfica y política que incluía a numerosas rancherías indígenas que apenas tenían conocimiento del hombre blanco, amén de cientos de paisajes que nunca habían sido visitados por los emisarios de la cultura occidental. Más que una división entre pueblos y culturas, era un reparto de zonas de influencia en el continente norteamericano a manera de un nuevo «tratado de Tordesillas». Dos naciones jóvenes (México y Estados Unidos) se disponían a expandirse en un espacio desconocido a la vez que se consolidaban como pueblos independientes. Identidad y colonización de frontera fueron dos procesos simultáneos que no tardaron en influirse mutuamente, aunque con resultados distintos. Los Estados Unidos extrajeron de esa frontera -gracias a la tesis de Frederick Jackson Turner ${ }^{4}$ - buena parte de las características (individualismo, iniciativa, optimismo, seguridad, laboriosidad...) con que quisieron modelar el presente y el futuro de la nación; mientras México se refugió en las provincias del centro, cuyo pasado y presente indígena sirvió de base al neoaztequismo y a la creación de una memoria histórica que siguió localizando en las desiertas regiones del norte las imágenes de barbaridad e inhumanidad que había heredado de la cultura occidental y prehispánica 5 .

Durante la segunda mitad del siglo XIX, varias comisiones de ingenieros americanos y mexicanos se afanaron por fijar en los mapas una línea que los separara definitivamente, aunque, en la práctica, no había hecho más que comenzar un proceso de unión comercial, laboral y humana cuyos resultados son cada día más complejos para los gobiernos y los no «fronterizos» de ambos lados. Tras la invasión norteamericana (1846) y la pérdida de gran parte del territorio mexicano en beneficio de los vecinos del norte (1848), nuevos tratados vinieron a engrandecer los dominios territoriales de los Estados Unidos, bien por ventas oficiales (Tratado de la Mesilla, de 1852) o por ocupaciones de hecho ${ }^{6}$. Incluso

4 Frontier in America. Enssays of Frederick Jackson Turner, Englewood Cliffs, Nueva Jersey, Prince Hall, 1961.

5 Agustín Basave Benitez, México mestizo. Análisis del nacionalismo mexicano en torno a la mestizofilia de Andrés Molina Enríquez, México, Fondod de Cultura Económica, 1992.

6 Luis BERLANDIER y Rafael CHOVEL, Diario de viaje de la comisión de límites que puso el gobierno de la República, bajo la dirección del Excmo. Sr. general de división D. Manuel de Mier y Terán, México, Tipografía de Juan R. Navarro, 1850. 
para finales del siglo XIX se seguía delimitando la frontera. En 1891 se organizaron dos comisiones para demarcar de nuevo la línea divisoria entre México y los Estados Unidos conforme a las convenciones del 29 de julio de 1882 y del 18 de febrero de 1889. Aunque el proyecto se inició como una comisión para recorrer la línea divisoria y restablecer los monumentos destruidos o averiados que antiguamente marcaban los límites entre las dos naciones, en la práctica resultó un descubrimiento en beneficio de México de 8.130 hectáreas (y sólo una pérdida de 708 hectáreas en la frontera californiana que, en buena lid, pasaron a manos de los norteamericanos). John Sherman, de la legación americana, señaló que: «Los adelantos de la ciencia, la perfección de los intrumentos y el uso del telégrafo permitieron a esta comisión descubrir los errores de la primera» ${ }^{7}$. Sin embargo, se estimó por muy caro el cambio de los mojones, por lo que se llegó al acuerdo de integrar a México una porción de terreno desierto en un punto determinado de la frontera.

Las distintas comisiones científicas encargadas de fijar la frontera durante la segunda mitad del siglo XIX recorrieron miles de millas de territorios desolados, levantando un buen número de obeliscos que servían más para justificar los gastos de la expedición que para dar a conocer el término o el inicio de dos naciones distintas. Antes de las caravanas, espiándoles en sus trabajos, y siguiéndoles sus huellas, los pueblos indios eran los invitados a unas ceremonias que nunca entendieron. Aunque hubo algunos encuentros pacíficos (la conferencia del 29 de junio de 1853 entre el comisionado Emory y Antonio Azul, de los pimas, Francisco Luke, de los cocomaricopas, y Ojo de Burro, de los pimas de Gila), lo cierto es que prevaleció la indiferencia y la abierta hostilidad. Los comisionados de ambos lados se quejaron a sus respectivos gobiernos sobre la destrucción de los monumentos levantados por parte de los indios fronterizos. Si cien años antes eran las imágenes religiosas y los ornamentos sagrados los que concentraban el odio de los indios ${ }^{8}$, ahora eran los extraños pináculos los protagonistas de sus «bárbaras» destrucciones. Y es que en el antiguo norte de México, a pesar de los cambios de soberanía, el problema principal para los gobiernos de Washigton y Ciudad de México fueron los pueblos nómadas y seminómadas que habitaban los áridos desiertos. El Tratado de Paz, Amistad, Límites y Arreglo Definitivo entre la República Mexicana y los Estados Unidos de América (1848), señalaba en su artículo XI que:

«En atención a que una gran parte de los territorios que por el presente tratado van a quedar para lo futuro dentro de los límites de los Estados-Unidos, se halla actualmente ocupada por tribus salvajes, que han de estar en adelante

7 Luis G. ZORRILlA, Monumentación de la frontera norte en el siglo XIX, Archivo Histórico Diplomático Mexicano, México, Secretaría de Relaciones Exteriores, 1981, p.446.

8 Carlos Manuel VALDÉs, La gente del mezquite. Los nómadas del noreste en la Colonia, México, CIESAS- Instituto Nacional Indigenista, 1995, pp.176-178.

R. I., 1999, n. $^{\circ} 216$ 
bajo la esclusiva autoridad del gobierno de los Estados Unidos, y cuyas incursiones sobre los distritos mexicanos serian en extremo perjudiciales, está solemnemente convenido que el mismo gobierno de los Estados-Unidos contendrá las indicadas incursiones por medio de la fuerza, siempre que así sea necesario; y cuando no pudiere prevenirlas, castigará y escarmentará a los invasores, exigiéndoles además la debida reparación: todo del mismo modo y con la misma diligencia y energía con que obraría si las incursiones se hubiesen meditado o ejecutado sobre territorios suyos o contra sus propios ciudadanos».

Pues bien, las reclamaciones nunca fueron atendidas -todo quedó en papel mojado- a pesar de que los pueblos de la frontera llevaron buena cuenta de lo destruido o robado por las partidas indígenas 9 . Todavía en 1880 se hicieron intentos por cobrar indemnizaciones al gobierno de los Estados Unidos. En un oficio fechado el 28 de febrero de ese año, el gobernador de Chihuahua giró órdenes al jefe político de Guerrero para que formulara un informe circunstanciado de los daños causados por los indios, en el que se comprendieran fechas, robos, personas afectadas, gastos de las campañas, etcétera. El gobernador indicó que era público que los apaches conducían el producto de sus razias a las reservas americanas, donde en teoría se encontraban vigilados por agentes oficiales norteamericanos. Sin embargo, a pesar de la claridad del tratado, y de la constancia en los archivos de cientos de ataques indígenas a las regiones fronterizas, no se ha encontrado hasta ahora ningún documento que pruebe el pago de responsabilidades estadounidenses por las acciones armadas de los indios. Por el contrario, las autoridades del norte del río Bravo vieron con desidia este punto del tratado hasta que lograron eliminarlo en un nuevo acuerdo con México.

Los ataques indígenas a las caravanas, ranchos y poblados mexicanos se intensificaron recién inaugurada la independencia de México. El equilibrio conseguido por las autoridades españolas a finales de la época colonial se rompió. Los apaches, comanches y otros pueblos indios aprovecharon la inestabilidad y debilidad del Estado Mexicano para caminar y asolar a lo largo y ancho de la frontera. El éxito de sus correrías les animó a viajar cada vez más hacia el sur con una arrogancia insólita, ya que llegaron a atacar ranchos y caminos de Zacatecas y Aguascalientes. Las consecuencias de las guerras indias son difíciles de evaluar: sólo con estudios regionales se podrá conocer el impacto de una prolongada situación de inestabilidad y violencia en las comunidades del norte de México, y no sólo estoy hablando de colonos blancos o mestizos, sino de comunidades in-

9 «Modelos según los cuales deben sustanciarse los expedientes de reclamos contra los Estados Unidos de Norteamérica, por daños y perjuicios causados por las tribus de indios procedentes del otro lado del Río Bravo del Norte, desde el mes de mayo de 1848 en que empezaron las incursiones de comanches y otras tribus». La información pertenece al excelente catálogo de Carlos Manuel VALDÉs e Ildefonso DÁVILA (coords.), Fuentes indias para la Historia India de Coahuila, Madrid, Fundación Histórica Tavera-Archivo Municipal de Saltillo, 1998, p. 226. 
dígenas, que, como los rarámuris (tarahumaras), sufrieron las cada vez más frecuentes razias apaches ${ }^{10}$.

Una primera mirada al tema da algo más que escalofríos: indignación. Carlos Pacheco, diputado secretario del Estado de Chihuahua se preguntaba en 1833: «¿qué es un miserable puñado de cobardes antropófagos, para mantener en continua zozobra a una sociedad organizada?». Esta sociedad, en nombre de su tranquilidad y sobrevivencia (en nombre de Dios y la Civilización) se dispuso a regular la caza de apaches, normando conforme a derecho y aprobando una ley según las facultades constitucionales del congreso del Estado (fechada el 12 de abril de 1848) que decía:

«1. Se declara que la guerra contra los indios bárbaros es la primera urgencia del estado.

2. Se faculta al gobierno del estado para que pueda hacer la guerra contratando voluntarios nacionales y extranjeros.

3. Los contratos o contratas que celebre el Gobierno serán bajo la base de cantidad determinada por cada indio muerto.

4. Los fondos que se destinen para la guerra serán los siguientes:

Primero: El producto de octavo de aumento sobre cada cajilla de cigarros y papel puros, desde que fue consignado al estado por virtud de la contrata de la venta.

Segundo: El producto del derecho de quintos en todo el estado.

Tercero: La cantidad disponible de los 32 mil pesos que se asignaron por el Decreto General de 16 de Octubre de 1848.

Cuarto: Las donaciones que se hagan por los particulares para esta guerra» ${ }^{11}$.

Mes y medio después se precisaron las cantidades a pagar: 200 pesos por cada indio de armas muerto y 250 pesos por cada guerrero prisionero. Las mujeres y menores de 14 años: 150 pesos.

Estas «enérgicas» medidas del gobierno eran la respuesta a los fracasos de las expediciones punitivas y de las conferencias de paz. La situación era caótica, pero sobre todo en las pequeñas comunidades aisladas en los campos o en la Sierra Madre Occidental. El más reciente trabajo de los historiadores saltillenses Carlos Manuel Valdés e Ildefonso Dávila, titulado Catálogo de fuentes indias para la historia de Coahuila (Madrid, 1998) lo demuestra. Otro trabajo reciente, Tierra de Libres, de Víctor Orozco (Chihuahua, 1995), explica cómo los pueblos del distrito de Guerrero aprendieron a defenderse de las continuas razias apaches que aprovechaban las estribaciones y valles del oeste chihuahuense para internar-

\footnotetext{
10 Un buen ejemplo es el libro de Víctor Orozco, Las guerras indias en la historia de Chihuahua. Primeras fases, México, Consejo Nacional para la Cultura y las Artes, 1992.

11 Silverio TLAPAPAL RASCÓN, «Las contratas de sangre en Chihuahua (1848-1850)», Cuadernos del Norte, 19, 1992, p.33.
}

R. I., 1999, n. ${ }^{\circ} 216$ 
se hasta el centro del país, y, en caso de contraataque, desaparecer entre las abruptas serranías de la Sierra Madre.

La guerra india significó, en primer lugar, destrucción de la riqueza. Numerosos ranchos quedaron despoblados, las comunicaciones interrumpidas, las familias destrozadas y las arcas estatales por lo general en bancarrota debido a las grandes sumas de dinero que los gobiernos provinciales debían erogar para pagar a los soldados y arreglar los destrozos. A la vez, la guerra desvalorizó la tierra de numerosas comarcas, al quedar abandonados una gran cantidad de terrenos, o al hacerse casi imposible su explotación. Algunos grandes propietarios se aprovecharon de esta situación a la larga, pues compraron los ranchos y minas a bajo precio o dictaminaron sobre su abandono. Evidentemente, una vez pacificada la comarca, los predios recuperaron o multiplicaron su antiguo valor ${ }^{12}$.

Otra consecuencia fue la pérdida de la seguridad jurídica. Por ejemplo, los grupos de soldados especializados en la guerra india (campañadores) reivindicaron tanto su derecho a la saca como la propiedad de los animales y bienes recuperados. De la misma forma, muchos acuerdos de paz con los indios incorporaban una cláusula por la que éstos retenían el producto de sus razias, quedando en ambos casos el propietario sin sus bienes. Como cabe suponer, estas prácticas aumentaban la inseguridad en los campos y desmoralizaba a los arriesgados habitantes de las zonas fronterizas. El caso se agravaba cuando el ranchero ni siquiera era dueño. Un ejemplo interesante de esta negativa situación lo podemos encontrar en la petición de un grupo de colonos de la hacienda de El Rosario (Chihuahua), nunca habitada por sus propietarios, quienes se dirigieron al jefe político del distrito para demandarle auxilios a fin de repoblar la citada hacienda, desprotegida por los ataques indios. Los peticionarios escribían:

«...que hace un año y seis meses que nuestros contemporáneos vecinos por temor de las incursiones de los bárbaros apaches abandonamos la frontera que como destacamento guarnecíamos en el punto del Rosario, aunque con los muy lamentables sacrificios por la ruinosa indigencia en que nos han dejado reducidos a la mendicidad; hoy reunidos de nuevo (...) nos hayamos en la disposición de volver a poblar la mencionada frontera que casi está sirviendo de albergue a nuestros contrarios enemigos (...) ocurrimos a usted impetrando los auxilios para que se nos provea de algunas yuntas de bueyes para el cultivo de las tierras y a la responsabilidad de pagarlas con semillas al precio de un peso por fanega de maíz (...) es innegable el interés que casi en lo general debe haber en que la actual frontera se cubra (...) y a más de lo dicho se nos conceda la garantía de evadirnos de acudir a las juntas y campañas por la escasez en que nos hallamos de cabalga-

12 Jane-Dale LLOYD, El proceso de modernización capitalista en el noroeste de Chihuahua, México, Universidad Iberoamericana, 1987. 
dura y la distancia que media del Rosario a esta villa, por la consecuencia de quedar expuestas nuestras numerosas e inocentes familias a ser sacrificadas... ${ }^{13}$

Como acertadamente ha señalado Víctor Orozco, el autor o autores del documento anterior utilizan el concepto frontera con un significado diferente al de línea que divide dos entidades políticas o geográficas. Alude a una zona poco dominada por los pobladores y soldados del norte, escasamente colonizada y con una alta operatividad de las bandas indígenas. Hay que recordar que grandes territorios de Sonora y Chihuahua formaban parte del espacio histórico y natural de los apaches y comanches, por lo que el enfrentamiento con éstos y otros pueblos indígenas se hizo cada vez más frecuente conforme avanzó el siglo XIX por la conquista del Oeste y la colonización del Norte fomentada por las naciones de ambos lados de la frontera.

Uno de los textos más importantes de los enfrentamientos en la frontera norte son las memorias de Gerónimo, famoso jefe apache recluido junto a parte de sus parientes en Fort Sill (Oklahoma) tras ser derrotado en 1886. El temido guerrero dictó su vida a S.M. Barret, inspector general de educación de Lawton (Oklahoma), entre 1905-1906, sirviendo de traductor otro apache, Asa Daklugie, hijo del mítico Jú. Es digno de destacar que Gerónimo sólo hablaba uno de los dialectos apaches y español, pero no inglés. Gerónimo contó que:

«En las numerosas guerras que libramos contra los mexicanos, resulté herido ocho veces (...). Yo mismo maté a muchos mexicanos. No sé cuántos exactamente, porque muchas veces no los contaba. Algunos no valía la pena contarlos, ésa es la verdad. Ha pasado mucho tiempo, pero sigo sin querer a los mexicanos. Conmigo siempre se han mostrado desleales y criminales. Estoy viejo ahora, y nunca más volveré a tomar el sendero de la guerra, pero si fuera joven y pudiera tomar el sendero de la guerra, me iría derecho hasta México» ${ }^{14}$.

Este fragmento de uno de los textos más importantes de la visión de los vencidos muestra la violencia y el odio que ambas partes llegaron a desarrollar, si bien, a la larga, los ejércitos norteamericanos y las partidas de guerreros mexicanos, estimulados con más dinero y premios conforme avanzaba la centuria, llevaron las de ganar.

13 Víctor Orozco Orozco, Tierra de Libres. Los pueblos del Distrito de Guerrero en el siglo XIX, México, Universidad Autónoma de Ciudad Juárez-Gobierno del Estado de Chihuahua, 1995, p. 77.

14 «El indio Gerónimo. Memorias», en Víctor OROzco (comp.), Las guerras indias en la Historia de Chihuahua, México, Universidad Autónoma de Ciudad Juárez-Instituto Chihuahuense de la Cultura, 1992, pp.391-458:424.

R. I., $1999, \mathrm{n}^{\circ} 216$ 


\section{LOS «HOMBRES LIBRES» Y LA SANTA DE CABORA}

El final de la guerra india fue acompañado de una repoblación del Norte. Frente a las grandes haciendas, regiones como el oeste de Chihuahua presentan un predominio de campesinos o labradores que, a fines del siglo, desarrollaron un notable espíritu de autonomía frente a los representantes de los estados y del gobierno central. La prolongada guerra con los indios había hecho nacer un sentimiento de orgullo colectivo y de resistencia a los mandatos externos, que pronto chocaron con los intereses de los políticos y los grandes hacendados. Como ha estudiado Víctor Orozco para el cantón de Guerrero, en el oeste de Chihuahua: «Esta mentalidad los hizo coincidir a menudo con la corriente histórica del liberalismo, enfrentada con los militares y los clérigos, representantes del antiguo régimen, cuyas instituciones suponían el sometimiento y la servidumbre en las grandes haciendas. Pero también hizo que al menos una buena porción de estas comunidades chocaran con el gobierno republicano, cuando éste, obligado por las circunstancias, decretó el pago de impuestos extraordinarios». Así nacieron los «hombres libres», quienes, en la coyuntura finisecular se transformaron de guerreros en contra de los indios a opositores del régimen porfirista sin apenas transición, constituyéndose en la base del ejército villista en los prolegómenos de la Revolución de 1910. Además, encontraron en la religión cristiana no católica defensora del status quo- un signo de identidad y un nuevo frente de oposición a sus tradicionales enemigos. No es por tanto casual que la frontera se hiciera «protestante», en particular en su variante congregacionista, pues la ausencia de ritos y su autonomía frente a las jerarquías se adaptaba muy bien a la mentalidad de estos orgullosos colonos ${ }^{15}$.

Los nuevos estudios regionales, realizados a partir de la documentación custodiada en los archivos locales y provinciales, tienen una importancia decisiva no sólo para entender la historia del Norte de México durante el siglo XIX, sino también para comprender la historia de la revolución mexicana de $1910^{16}$. En buena parte de la historiografía norteamericana y mexicana, los soldados del ejército maderista y de la División del Norte fueron considerados como hombres desarraigados, principalmente vaqueros, vagabundos y bandidos. Otros los contemplaron como campesinos muy parecidos a los de las comunidades que siguieron a Emiliano Zapata en el sur. Sin embargo, las nuevas investigaciones han demostrado que ninguna de estas descripciones eran correctas, sino que los hombres de Guerrero fueron esencialmente rancheros independientes cuyas raíces se

15 Jean Pierre BASTIAN, Los disidentes. Sociedades protestantes y revolución en México, 1872-1911, México, Fondo de Cultura Económica-El Colegio de México, 1989.

16 Sobre el tema, véase el libro de Linda HALl y Don M. COERVER, Revolución en la frontera, México, Consejo Nacional para la Cultura y las Artes, 1995. 
encuentran en el período colonial (cuando les fueron concedidas tierras por la Corona para pelear contra los apaches).

En definitiva, el final de la guerras indias en la década de los ochenta fue acompañado del regreso de los hacendados y los representantes gubernamentales a grandes regiones de la frontera con el fin de imponer su ley. Los historiadores han resaltado dos procesos simultáneos, el ya citado final de las incursiones apaches y la llegada del ferrocaril, lo que permitía la pacificación del territorio, la explotación de los recursos y la consolidación de los mercados regionales y fronterizos ${ }^{17}$. Como ha señalado Alan Knight, estos procesos fomentaron la protesta rural por el despojo de tierras y la incorporación de muchos poblados -hasta entonces alejados del poder central- a la vida nacional. Las rebeliones rurales con un período álgido entre 1891-1893- tuvieron un carácter autonomista. Los campesinos, que habían permanecido hasta entonces fuera del control de los terratenientes y sin la intromisión del gobierno central, se rebelaron para mantener su tradicional forma de vida. «Los aldeanos deseaban verse libres del agobio del gobierno -escribe Alan Knight-; les disgustaba el jefe político, el cobrador de impuestos, el juez, el ejército [en especial el sargento de reclutamiento] y la policía. Quizá la expresión mejor y más dramática de esa actitud la mostró Cruz Chávez, el jefe de la rebelión de Tomóchic de 1892, quien proclamó que todo lo que él y sus compañeros aldeanos deseaban era que «nadie se metiera con ellos, ni los molestara para nada, ni interviniera en sus asuntos», y que, en defensa de estas peticiones modestas, «se consideraban bastantes para resistir las 60.000 bayonetas de Porfirio Díaz».

Los movimientos de protesta de la frontera norte de México son un tema de gran complejidad, abordado con desigual fortuna por numerosos historiadores. Dado lo breve de este trabajo sólo me detendré en un aspecto que ha polarizado gran parte de estos estudios, el componente milenarista, con el afán de introducir al lector en estos temas e indicarle los principales aportes bibliográficos, relegando para otro momento las investigaciones que vengo realizando sobre la más importante de las visionarias del norte, la famosa Teresa Urrea, la santa de Cabora. Esta joven mestiza fascinó a miles de seguidores, entre ellos, a gran cantidad de indios mayos y yaquis, en los que despertaba un enorme interés por las profecías y la experiencia mística. Siguiendo su estela, no tardaron en aparecer en varias regiones de Sonora numerosos cristos, santos y santas en vida que convivieron con los populares «elegidos» católicos, conocidos gracias a los relatos de los sacerdotes, los libros de devociones y las imágenes sagradas. Esta constelación de santos vivientes fue aumentando con los años: san Juan, san Luis, san Ireneo, La Luz, santa Camila, santa Isabel, santa Agustina, etcétera, atrayendo a miles de adeptos de entre las

17 Mark WaSERMANn, Capitalistas, caciques y revolución. La familia Terrazas en Chihuahua, 1854-1911, México, Editorial Grijalbo, 1987.

R. I., $1999, \mathrm{n}^{\circ} 216$ 
capas bajas de la población. Los historiadores han encontrado, además, que algunos de ellos tenían relaciones directas con los rebeldes yaquis ${ }^{18}$.

Aunque son numerosos los casos de revueltas asociadas a la figura de Teresa, la más famosa sería la realizada por los habitantes del pequeño pueblo de Tomóchic en $1891^{19}$. Alentados por las doctrinas milenaristas, un grupo de habitantes del citado poblado fueron a visitar a dos viejitos que se autoproclamaban como el Cristo de Chopeque y la Virgen de Guadalupe, quienes les revelaron que pronto estarían en guerra con las autoridades porfiristas, pero que no debían de temer nada ya que se encontraban bajo la protección de la santa de Cabora. De regreso a Tomochic, los romeros estaban convencidos de su superioridad y de estar revestidos de una coraza divina, por lo que se dirigieron a Cabora (Sonora) en busca de la joven vidente con fama de santidad.

Pero, ¿quién era esta Teresa Urrea, que tanto problemas estaba dando al todopoderoso Porfirio Díaz?. Teresa Urrea Chávez, hija natural de Tomás Urrea, rico hacendado sonorense, y de Cayetana Chávez, india tehueca, nació el 15 de octubre de 1873 en el pueblo de Ocoroni, Sinaloa. Desde su nacimiento vivió humildemente al lado de su madre, hasta que, en 1888, se marchó a vivir con su padre a la hacienda de Cabora -entre los ríos Yaqui y Mayo-, en donde sufrió un ataque de catalepsia que la mantuvo al borde de la muerte durante tres meses. Ya restablecida, Teresa empezó a curar a los vecinos con la imposición de manos y a proclamar que había hablado con el Espíritu Santo.

En poco tiempo, la llamada popularmente santa de Cabora desarrolló una enorme influencia entre los indios y mestizos de Sonora, Sinaloa y Chihuahua, elaborando un discurso político en contra de las autoridades políticas y eclesiásticas influida por su padre Tomás Urrea -liberal, anticlerical, antiporfirista y miembro de una poderosa familia, los Urrea- y por Lauro Aguirre -ingeniero chihuahuense, metodista, espiritista, periodista, y político antiporfirista- que se pasaba la vida planeando revoluciones. Ambos, Tomás Urrea y Lauro Aguirre ejercieron una gran influencia sobre Teresa, quien fue visitada en Cabora, entre 1889 y 1892 , por más de 200.000 personas en busca de curación ${ }^{20}$. La aparición

18 Por ejemplo, san Damián, joven sonorense, sobrino de Ciriaco Quijano, uno de los oficiales de Cajeme, famoso rebelde yaqui. Sobre el tema, véase Cécile GouY-GILBERT, Una resistencia india. Los yaquis, México, Instituto Nacional Indigenista, 1985.

19 La historiografía sobre la rebelión y destrucción de Tomóchic es muy numerosa. Tres de los últimos libros son Rubén OsoRio, Tomóchic en llamas, México, Consejo Nacional para la Cultura y las Artes, 1995; Lilián Illades AguiAR, La rebelión de Tomóchic, México, Instituto Nacional de Antropología e Historia, 1993; y Antonio SABORTI, Los doblados de Tomóchic. Un episodio de historia y literatura, México, Cal y Arena, 1994. Un clásico de la revuelta es Francisco R. ALMADA, La rebelión de Tomóchoc, Chihuahua, Talleres Linotipográficos del Gobierno del Estado, 1938. La gran popularidad del tema se debe a la novela de Heriberto Frías, Tomochic, México, Porrúa, 1968; la primera edición es de 1893.

20 El dato lo proporciona Brianda DoMECQ, La insólita historia de la Santa de Cabora, México, Planeta, 1990, pp.45-54. 
de su nombre en varias sublevaciones (reuniones de los santos en Sonora y Tomochic en Chihuahua) y sus reiterados ataques a la iglesia católica decidieron a las autoridades a enviarla al exilio en los Estados Unidos, donde inició una nueva vida.

En 1892, año en que los españoles festejaban los 400 años del descubrimiento de América, la frontera norte de sus antiguas posesiones vivía un cambio muy importante en su historia. En ese año, se produjo en México la última incursión apache (al menos que haya sido registrada) y fue sofocado el levantamiento de Tomóchic (Chihuahua), calificado como «la revolución adelantada» ${ }^{21}$. En 1992, los tomochtecos celebraron el primer centenario de la destrucción de su pueblo, mientras oían a los comentaristas de Televisa relatar el comienzo de las Olimpiadas de Barcelona y la llegada de Salinas de Gortari a la Expo 92 de Sevi1la. Como ha escrito Michel de Certeau: «La ciencia histórica ve crecer las regiones silenciosas de donde ha estado ausente» ${ }^{22}$.

While Spain and other European and American countries celebrated the IV Centenario del Descubrimiento de América in 1892, the population at the northern part of Mexico knew about the last apache incursion in Mexican territory and the rebelion of the neighbours of the Temochic little town. Both events will be used to analyze the situation of overarching violence in the North and surge of a feeling of freedom, independence and discontentedness among the authorities which would lead to the 1910 Revolution.

21 Jesús VARGAS VALDEZ (compilador), Tomóchic: la revolución adelantada. Resistencia y lucha de un pueblo de Chihuahua contra el sistema porfirista (1891-1892), 2 vols., México, Universidad Autónoma de Ciudad Juárez, 1994.

22 Michel de CERTEAU, La escritura de la historia, México, Universidad Iberoamericana, 1993, pp. 55-56.

R. I., 1999, n. $^{\circ} 216$ 